\title{
Artifacts and Attachment: A Post-Script Philosophy of Mediation
}

\author{
Peter-Paul Verbeek
}

\section{Introduction}

What should one think of things? This question is a pressing one, now that Technology Studies has discovered artifacts as the objects of inquiry par excellence. Societies are not only held together by social relations and institutions, as sociologists and anthropologists claim, but by things as well. Technology should be analysed not only in terms of the social processes in which it is constructed, but also in terms of the role it plays in social processes itself.

Within Technology Studies, the predominant vocabulary for understanding the role of artifacts in society is offered by actor-network theory. Bruno Latour, one of its major representatives, ${ }^{1}$ maintains that the social sciences' exclusive focus on humans should be abandoned. The so-called "principle of symmetry" is the most notable feature of Latour's approach, entailing that humans and nonhuman entities should be studied symmetrically. No a priori distinctions should be made between them if we are to understand what is actually happening in society. Not only humans, but also "nonhumans", or conjunctions of humans and nonhumans, should be understood as actors.

An important concept of actor-network theory for analysing these "thingly actions" is "script" (Akrich 1992). This concept indicates that things-in-use can "prescribe" specific forms of action, much like the script of a theatre play, which orchestrates what happens on stage. A plastic coffee cup, for instance, has the script "throw me away after use"; the cameras along many roads in the Netherlands have the script "don't drive faster than $50 \mathrm{~km} / \mathrm{h}$ ". Artifacts are not passive and inert entities. They actively co-shape what actors do.

The actor-network vocabulary for understanding this active role of artifacts in society has proven to be very fertile. Yet, it could benefit from several additions. This becomes clear when it is translated into the context of industrial design. Within that discipline, a discussion is currently waging on ecodesign, which aims at finding criteria for designing sustainable products. In 
this discussion, the Dutch industrial designers association "Eternally Yours" takes an unorthodox stance.

In contrast to the common strategy of trying to reduce pollution in the production, consumption, and waste stages of a product's life cycle, Eternally Yours is looking for ways to enhance product longevity. The primary environmental problem concerning consumer products is, Eternally Yours maintains, that most products are thrown away long before they are actually worn out. Designing clean products does not sufficiently address this problem. Products that are truly environmentally friendly should also create some kind of attachment between their users and themselves, so that they can be cherished throughout their lifespan instead of being thrown away prematurely.

Attempts to enhance the attachment between people and products require an understanding of this attachment, especially with regard to the way in which products themselves can stimulate its generation. The work of Eternally Yours thus raises the question of how the relationships between humans and artifacts can be understood. It will appear that Latour's vocabulary is helpful in answering this question, but that it needs to be augmented in order to do full justice to the role of things in people's everyday lives. I shall develop this augmentation by reinterpreting phenomenology, and by elaborating it literally into a post-script philosophy of technical mediation.

\section{Eternally Yours}

The major aim of the Dutch industrial-designer association "Eternally Yours" is to develop innovative ideas for "sustainable design" (Van Hinte 1997)..$^{2}$ It considers the current dominant approach within eco-design which focusses on life cycle analysis (LCA) - too superficial to be genuinely effective. Life cycle analyses anticipate the pollution caused by products in the different stages of their life cycles: production, consumption, and waste. LCA may make it possible to design products that are friendlier to the environment, but according to Eternally Yours, it overlooks the most fundamental problem: the short lifespan of consumer goods. In our throwaway culture, many products are discarded while they remain entirely capable of carrying out their function. Making products less polluting, therefore, is not enough. Environmental pressure will remain unabatedly high as long as all those "clean" products keep being thrown away and replaced as rapidly as is currently the case.

Eternally Yours' worries are not restricted to obvious throwaway products 
like disposable teaspoons and cups. Research for the Dutch Ministry of Environmental Affairs has shown that a large proportion of our everyday user objects, like hi-fi equipment, stoves, razors, and computers, is discarded although the objects still function well (Eternally Yours 1997, 4). Even worse, some products do not even reach the market. Brand new harddisks are destroyed regularly by recycling companies because they have already become outdated before they were even sold.

The environmental crisis, according to Eternally Yours, is not only a technological problem, but a cultural one as well. The interesting thing about Eternally Yours is that it does not try to evoke the cultural change it considers necessary by creating awareness, but by rearranging material culture. It looks for ways to stimulate longevity. Eternally Yours discerns three dimensions in the lifespan of products: a technical, an economical, and a psychological dimension. Products can turn into waste because they are simply broken and can no longer be repaired, because they are replaced by newer models, or because they no longer fit people's preferences and tastes. Of these, Eternally Yours regards the psychological lifespan as the most important (Muis et al. 1997). Many products are discarded because their psychological time is up. In order to create longevity, therefore, Eternally Yours seeks to design things that invite people to use and cherish them as long as possible. "It's time for a new generation of products that can age slowly and in a dignified way, become our partners in life and support our memories," as the Italian designer Ezio Manzini put it on Eternally Yours' letter head.

The crucial question for sustainable design is therefore: how can the psychological lifespan of products be prolonged? How can things stimulate the forging of a bond between their users and themselves? In three subprograms, Eternally Yours develops ideas to find answers to this question. In the program "Shape 'n Surface", it searches for forms and materials that could create longevity. Materials are being tested that do not become less attractive through aging but have "quality of wear". Leather, for instance, is generally found more beautiful when it has been used for some time, whereas a shiny polished chrome surface looks worn out with the first scratch. A good example of a design within this program is the upholstery of a couch that was designed by Sigrid Smits. An initially invisible pattern is stitched into the velvet that is used for it. When the couch has been used for a while, the pattern gradually becomes visible (Muis et al. 1997). Instead of aging in an unattractive way, this couch renews itself as it ages.

The second Eternally Yours subprogram called "Sales 'n Services" pays attention to the ways in which the services around products can influence their lifespan. The availability of repair and upgrading services can prevent people 
from discarding products prematurely. Companies can shift their core activities from continuously producing and selling new products to maintaining sustainable relations with customers.

The third subprogram, "Signs ' $n$ Scripts", investigates the role of the semiotic and symbolic aspects ("signs") of things in their lifespan, and their implicit prescriptions about how to use them ("scripts"). Stories around products, for instance, can give them more "character", like a Nikon advertisement some time ago, showing a camera that had been lying on the bottom of the ocean for ten years but still worked. This camera is not portrayed as the latest model with the newest features, but as a reliable product the owner can be proud of. The bond between people and products can also be influenced by scripts: things can create attachment by demanding that they be dealt with in a certain way. This aspect of products will be elaborated later in this chapter.

To elaborate these programs, Eternally Yours needs a vision of products that goes beyond the standard approaches within industrial design. Products are commonly approached in terms of their functionality on the one hand, and their style and meaning on the other. They are designed to work and, as a semiotic surplus to their functionality, to embody a style that fits their intended owners. In our postmodern consumption society, products should not only work, but also be expressions of lifestyles. For example, Braun manager Godehard Günther says in a textbook for industrial designers: "We do not sell devices, but a way of living". The French suitcase company Louis Vuitton adds: "Of course we produce top solid travel equipment, but we also sell myths and dreams, a certain way of travelling. Luxury, independence, and a feeling of flexibility are what characterise the owner of a Vuitton suitcase" (Bürdek 1996, 228 - my translation).

To Eternally Yours, however, functional and semiotic approaches to things do not suffice. If products were only designed from the perspective of their functions, people's attachment would not concern the products themselves, but only what the products do for them. People would not care whether it is this specific product they are dealing with or not. In Albert Borgmann's terms, it would be at best the commodity delivered by a product that would matter, not the product itself, i.e., the machinery that does all the work (Borgmann 1984). Conversely, if things were only present as signs for lifestyles and identities, people could only get attached to these signs, not to the things that carry them. If products are to invite us to get attached to them, therefore, they should not be present to people as mere carriers of functionality and meaning, but also as material entities. The attachment they enable should not only concern their functions or meanings, but the products themselves.

Thus from a practical point of view, Eternally Yours stumbled upon the 
importance of the materiality of things. But how should this materiality be conceptualised? How can one do justice to it when thinking about things without recurring to a naturalistic or naive realist position which pretends to be able to get in touch with "things themselves"?

\section{Conceptualising materiality}

Latour's theory of technical mediation offers a way to do justice to this materiality of things. I shall limit myself here to the way he developed his position in the articles Where Are the Missing Masses? - the sociology of a few mundane artifacts (1992) and On Technical Mediation (1994), which re-appeared in a slightly adapted form in Pandora's Hope (1999 ${ }^{\text {a }}$ ) as "A Collective of Humans and Nonhumans". As pointed out in the introduction, Latour proposes treating people and things ("humans" and "nonhumans") symmetrically. Actions are usually performed by compositions of humans and nonhumans. If I cycle to the university where I work, my travelling is performed jointly by my bicycle and I. There is neither any biking without me, nor without my bicycle. The nonhuman parts of such compositions should not be understood as passive and neutral instruments. They actively co-shape the action that is performed, that is, they co-act. Without a bicycle, my travel would be entirely different, and so would my contact with my surroundings.

Latour's principle of symmetry is of great importance to developing a more material way of thinking about things. Not only does it show that things have a capacity to act, but also that they have this capacity by virtue of their materiality: their concrete "thingly" presence. The way my bicycle mediates my contact with the landscape is not part of its functionality or style. The specific way in which the bicycle, as a physical object, enables me to go to work organises my relation with the environment in a specific way. This "surplus" of what things do besides function can be described as mediation.

To Latour, mediation primarily concerns action. However, he is no classical actiontheorist. In his approach, "action" does not indicate the conscious activities of intentional subjects, but simply all that is "happening", which, therefore, leaves traces on reality. Mediating action is co-shaping what is happening. Artifacts can play such a mediating role, for instance, by demanding that they be dealt with in a certain way. To mention some of Latour's examples, speed bumps mediate people's driving behaviour by encouraging them to drive slowly. Door springs mediate the speed with which people can enter a building, by giving them only a certain amount of time to enter. Heavy weights attached to hotel keys mediate whether or not people return those 
keys to the reception desk, because they are usually too cumbersome to carry around for a long time. The mediation of action, according to Latour, has the form of "prescriptions" that can be expressed in language as a "script", a series of instructions on how to act. The speed bump mentioned, for instance, has the script "slow down when you approach me"; a plastic coffee cup says "throw me away after use", as was cited in the introduction. Things mediate action here as material things, not only as carriers of signs or functions. A traffic sign makes people slow down in quite a different way - if it does so at all - and the function of a coffee cup does not include of making people throw it away.

In On Technical Mediation Latour develops four concepts to help understand the mediating role of artifacts. He discerns translation as the first meaning of "mediation". When artifacts mediate, they translate what Latour calls "programs of action". If someone is angry with somebody else, he or she might have the program of action "take revenge". If the anger is very strong, and there happens to be a gun around, this program of action could be translated into "shoot that person". The program of action is then translated into a new one, and along with this, both the angry person and the gun have changed as the person becomes a potential killer and the gun, a potential murder weapon instead of being just a deterrent object lying about. In this translation, both human and nonhuman aspects play a role. The human intention to express anger and the nonhuman function of the gun to shoot a bullet merge into the hybrid of "a person with a gun", which can only be understood by taking both its human and its nonhuman aspects into account.

This emergence of hybrids can be indicated by the second term from Latour's vocabulary of mediation: composition. Mediation consists of enabling the generation of new programs of action on the basis of the newly developing relations between the actants in question. This implies that the new program of action is owned by a "composite actant", and that responsibility for the resulting action should be spread among all actants involved. "Action is simply not a property of humans but of an association of actants" (Latour 1994,35).

Mediation thus consists of mixing humans and nonhumans. This mixing work usually remains hidden, however. Most of the time it is "black-boxed": the composite actant is taken for granted, making the "joint production of actors and artifacts entirely opaque" (Latour 1994,36). This reversible black-boxing is the third meaning of "mediation". To return to a previous example, all the work that has been done to design and produce a bicycle remains concealed. But when the chain runs from the sprocket, suddenly all kinds of entities "materialise" around the bike, as Latour would phrase it: a sprocket and a 
chain, which were not explicitly observed when biking, a repair person, the tools needed to repair the bike. All these entities are required to make the bike work as they are mixed together into the hybrid we call a bicycle. They therefore mediate my relation with my bike, and make it possible for me to have a bicycle that mediates my going to work, and especially, the way in which "I" do that.

The fourth and last term in Latour's vocabulary of mediation is delegation. Latour calls this the "most important meaning of mediation" (Latour 1994, 38). The concept of delegation indicates that programs of action can be "inscribed" into artifacts. The speed bump is a good example of this, according to Latour. If local authorities want people to drive slower in certain areas, they can do several things. They can put traffic signs along the road with an indication of the maximum speed allowed, put a policeman near the signs, or install a piece of concrete that is charged with the task of ensuring that people do not drive too fast. The program of action "make drivers slow down" is thus inscribed into a piece of concrete, which now becomes a "speed bump" with the script "drive slowly or damage your shock absorbers". Such delegations, according to Latour, enable a remarkable combination of presence and absence. The past action of an absent actor - the designer of the speed bump, or the mayor who insisted that the bump be placed - exerts influence on people's behaviour here and now.

These four aspects of mediation are closely connected. With regard to the speed bump, the authorities allied themselves to a piece of concrete (composition) and conveyed all that is needed for the realisation of their goal to the speed bump (delegation); after this, the bump can handle things by itself (black-boxing), because it changes the program of action of drivers from "driving slowly because of responsibility" into "driving slowly in order to save my shock absorbers" (translation). Translation, composition, reversible black-boxing, and delegation each form an aspect of technical mediation that could not exist without the others.

\section{Delegation and symmetry}

Latour's approach to things can be helpful to the Eternally Yours program. He shows that products have "scripts": they mediate action. Artifacts influence the way in which people do things, and this influence could be deliberately inscribed into them. To Eternally Yours, the most interesting scripts are those that evoke attachment between products and user which therefore stimulates people to throw away products less quickly. Sustainable products should in- 
vite people to develop a durable relationship with them. When trying to imagine what inscriptions that promote this kind of attachment might look like, however, it becomes clear that Latour's theory of mediation could benefit from some refinement and addition.

People can only develop a durable relationship with artifacts if what matters is not just a matter of style or function. After all, other artifacts could embody the same meaningfulness or functionality, but no other artifact can be this specific material thing, here and now. If someone is only attached to the style of a product, this product could as well be replaced by another one with the same sign value or the same iconography for the lifestyle this person wishes to be associated with. If it is only the function of a product that matters, then it could just as easily be replaced by an artifact functioning equally well or even better. In order to create attachment between people and products, products should be present and applicable in terms of their materiality, and not only their functionality or meaningfulness.

In order to be present to people in a material way, products could be designed to engage users explicitly in their function - including their durability, repair, and upgrading. If people need to interact with a product, their attention is not only directed at what it accomplishes or expresses, but also at the product itself. Many of Eternally Yours' solutions actually work this way: they engage people with their materiality. The stitched velvet mentioned above involves people in the wearing process. Upgradable and repairable products make people part of their aging and maintenance processes.

When trying to conceptualise how such "engaging products" can be present for people, however, it appears that it is not so much delegations from humans to things that are relevant here, but delegations from things to humans. If people are to be involved in the functioning of products, these products should delegate specific tasks and responsibilities to people. Delegations of this kind are underexposed in Latour's analysis of technical mediation. In his examples, Latour focusses on delegations from humans to nonhumans. The speed bump, key weight, and door-spring aforementioned do what they do because people told them so; in other words, officials have bumps installed because they want people to drive slowly; housekeepers install door-springs to prevent draughts; hotel owners attach weights to their keys to stimulate guests to return them to reception when leaving the hotel.

This one-sided focus raises the suspicion of asymmetry. This suspicion is reinforced by Latour's use of the concept of "inscription". Scripts are supposed to be the products of "inscribing", i.e., they are reducible to human activities. The same line of thought can be found with Akrich, when she first introduced the "script" concept: "Designers thus define actors with specific 
tastes, competencies, motives, aspirations, political prejudices, and the rest (...) A large part of the work of innovators is that of 'inscribing' this vision of (...) the world in the technical content of the new object. I will call the end product of this work a 'script' or a 'scenario'" (1992, 208; her emphasis). Both Latour and Akrich see scripts as the result of "inscriptions" - and inscription is an asymmetrical concept, since only humans have the ability to inscribe.

There is no real asymmetry involved here, however. Implicitly, Latour does discuss delegations vice versa: from nonhumans to humans. In Where Are the Missing Masses?, for instance, he expresses his admiration for a hydraulic door closer, because it easily absorbs the energy of those who open the door, retains it, and then gives it back slowly "with a subtle type of implacable firmness that one could expect from a well-trained butler" (Latour 1992, 233). This door-closer delegates to people the delivery of the energy it needs to close the door after it has been opened. Openness to delegation of this kind is crucial because, otherwise, only those forms of mediation that are explicitly intended by humans can be perceived, whereas things often do more than that. A revolving door has been delegated the task of keeping out draughts, while still maintaining the possibility of entering a building. That it also keeps out people in a wheelchair was nobody's explicit intention. Nor did the designers of the hydraulic door-closer intend them to discriminate against children and elderly people who are not strong enough to open them (Latour 1992, 234).

Yet, Latour's focus on delegation and inscription remains remarkable. If we are to understand the ways in which artifacts mediate, it does not matter all that much how they came to do so. What is important is that they play mediating roles, and the most relevant question to an analysis of technical mediation is how they do this. Focussing on the generation of the mediating roles of things could be seen as a relic from the early days in STs, when the ambition was to show that "facts" or "technologies" are actually contingent outcomes of processes of construction in which many actants interact. This deconstructionist approach aimed to unravel how entities come to be what they are. An analysis of the mediating role of artifacts can take the constructedness of this role for granted, however. For the understanding of technical mediation, the inscription processes and delegations from humans to nonhumans may remain black-boxed. Only the mediating role itself is relevant here, not its origins.

In their research into drug users and amateur musicians, Emilie Gomart and Antoine Hennion also observe the limitations of understanding mediation in terms of "inscriptions" and "delegations". In their view, concepts like these "render" objects "as prolongations of actions already initiated elsewhere; moreover, these object-mediators do not just repeat and relay actions 
but also transform these in surprising ways" (Gomart and Hennion 1999, 225). Their solution is to replace the concept of "action" with that of "events". The attachment between people and drugs or music cannot be adequately understood in terms of "action": the experiences of drug users and amateur musicians are events which "cannot be reduced to an interaction of causal objects and intentional persons" (Gomart and Hennion 1999, 226). The role of the "things" involved in these events (the drugs and records) should not be understood in terms of what has been delegated to them. Rather, they are "the locus of an event", as Gomart and Hennion phrase it: "There, in that encounter, the user is seized at those very points of asperity (or affordance) that are made possible and relevant by the sophistication of his/her own practices and vocabularies, as well as by the properties of the objects used" (Gomart and Hennion 1999, 243).

Although Eternally Yours needs somewhat different forms of attachment than that of drug users and music amateurs, Gomart and Hennion are right when they say that mediating artifacts should be approached as entities around which events occur, not as the outcomes of processes of interaction. This change of perspective creates the space necessary to see how artifacts actively co-shape the events around them, and to understand these events not only in terms of action but in terms of experiences as well. Delegations from things to people, not from people to things, form one way in which artifacts mediate what happens around them - a way that is particularly important to Eternally Yours. The attachment between users and industrial products that can come about in this mediation is less intense than that of drug users and amateur musicians. Where the latter are "seized" by the artifacts that mediate their experiences, the former are "engaged" by products that delegate tasks to them. Nonetheless, the structure of both attachments is the same. Just as the experience of drugs and music is always a blend of activity and passivity, striving and being seized - the users of engaging products both actively use the artifact and are used by it.

In order to be really helpful to Eternally Yours, this "expansion" of ANT needs to be carried a bit further. Not only the structure of attachment should be analysed, as was done by Gomart and Hennion, but also the role artifacts play in the realisation of this attachment. An analysis of this role should go beyond the concept of "script" if we are serious about replacing "action" with "events" in our analysis. The "script" concept remains biased toward action: scripts are defined as sets of "prescriptions" on how to act (Latour 1992, 232233). And, more importantly, it erroneously suggests that mediation is a property of the artifacts themselves, not of the relationship between humans and artifacts. Artifacts are supposed to "have" scripts where the mediating forces 
that co-shape the events around artifacts are localised in the artifacts themselves. After all, if this were not the case, it would not make sense to speak of delegations "to" nonhumans and inscriptions "in" artifacts.

An alternative interpretation of technical mediation can be developed, however, that does not localise mediation in the mediating artifacts themselves, but in the relationship between people and artifacts, or better such as in the "artifactually" mediated relation between humans and their environment. In order to understand the "encounter" between humans and objects as Gomart and Hennion call it - in a more detailed way than AN T does, a reinterpretation of phenomenology offers a suitable framework. In this reinterpretation, classical phenomenology is freed from the essentialist and romantic connotations that have become connected to it over the past century. Within the resulting "postphenomenological" perspective - to use a term of Don Ihde in a somewhat different way than he does himself 3 - phenomenology is understood as analysing the relationships between humans and their world. Technical mediation should be localised precisely in these relationships.

\section{A postphenomenology of attachment}

\section{Postphenomenology and actor-network theory}

During the first half of the 2oth century, phenomenology was an influential philosophical movement. However, its influence has steadily waned over the past few decades. Phenomenology aroused the suspicion of being a romantic and essentialist approach. It was increasingly at odds with the rising contextualism in philosophy, brought about by the emphasis on both linguistics and postmodernism. Nevertheless, it is possible to formulate a phenomenological perspective that leaves these problematic connotations behind. This "postphenomenological" perspective appears to complement ANT in several ways.

Like actor-network theory, phenomenology developed in opposition to the realism and positivism of the sciences. Seen from a present-day perspective, however, it ultimately did this in a highly problematic way. Against the claim of the sciences that they would reveal reality as it "truly" is, phenomenologists like Merleau-Ponty stated that scientifically interpreted reality was actually a derivative from a more fundamental one - that of the reality of everyday experience. Only on the basis of experiencing the meaningful, everyday world, Merleau Ponty claimed, can the sciences build their abstractions. ${ }^{4}$ In opposition to the sciences, therefore, he saw phenomenology as a method for "describing" the world, not "analysing" it. 5 
Classical phenomenology - at least some positions within it - thus tried to counter the sciences with an alternative claim. Not science but phenomenology itself would be able to get into contact with "reality itself". This "phenomenological realism" has become problematic in the light of the currently dominant view that the relationship between humans and reality is always mediated and contextual. The romantic search for "authentic" access to reality, in order to overcome the alienation brought about by science, ultimately got phenomenology into trouble.

However, phenomenology does not need to be just as a philosophy of alienation. Classical phenomenologists saw it as their ultimate goal to "describe the world" (Merleau-Ponty) or to understand the "intuition of essences" (Husserl) or the "self-manifestation of being" (Heidegger), but in their attempts to reach these goals, they accomplished something else as well. In order to understand these "essences", "world", and "being", they all developed analyses of the relationships between humans and reality. Husserl analysed this relationship in terms of consciousness, Merleau-Ponty in terms of perception, Heidegger in terms of being-in-the-world. It would be more modest and less problematic, therefore, to understand phenomenology as analysing the relationships between humans and their world. ${ }^{6}$ In this way, the pretension to possess the key to authentic contact with reality is relinquished.

Common to all classical phenomenological analyses of human-world relationships is that they contain a variant of Husserl's concept of "intentionality". To Husserl, this concept made it possible to navigate between the cliffs of realism (the idea that the world can be known as it is "in itself") on the one hand, and idealism (the idea that the world we know is a product of our consciousness) on the other. Husserl claimed that subjects and objects cannot be separated in this rigid way, but are instead always interrelated. The concept of "intentionality" indicates that humans are continually directed towards their world. People cannot help but be involved with their world as they are always experiencing it, and it is the only place where they can live their lives. In everyday life, subject and object are never separated, as realism and idealism suggest, but are always already interrelated.

Radically interpreted, this concept of intentionality is able to avoid the pitfalls of romanticism and essentialism mentioned above. Subject and object should not be seen as simply "related to each other"; they constitute each other in their interrelation. In their mutual relationship, they co-shape one another. In each situation, humans are what they are on the basis of their relation to their world, and their world is what it is on the basis of their relation to it. In their involvement with reality, humans necessarily disclose it in a specific way, and are themselves constituted in specific ways. In the interrelation of hu- 
mans and world, therefore, a specific "objectivity" of a world and a specific "subjectivity" of humans are generated. It should be mentioned that none of the two poles may be made absolute here. People cannot arbitrarily disclose any world, since there is always "something" that is disclosed as a world. Conversely, the fact that humans are what they are on the basis of their relation to the world does not imply that they are entirely determined by it.

As later phenomenology did - including the later Husserl himself - this view of phenomenology replaces Husserl's transcendental subject by an existential subject, and does not conceive the world as a collection of "objects", but as a lifeworld. The world is the place where humans realise their existence, and which is continually experienced and interpreted by them. What sets my reinterpretation of phenomenology apart from classical phenomenology, however, is the centrality of the notion of mutual constitution and, as will become clear below, the notion of the mediated character of this constitution. Husserl, too, used the concept of "constitution" in his work, but he localised it exclusively on the subjective side: he tried to understand how subjects constitute a world. As opposed to this, I localise constitution in the interrelation of subjects and objects. Not only objects but subjects are also constituted in the intentionality relationship that exists between them.

The phenomenological perspective I defend here has the same symmetrical intentions as are present in Latour's work in that it tries to overcome the "Grand Canyon" between subject and object by showing that both cannot exist separately. It even goes one step further, by stating that subject and object constitute each other. The resulting "postphenomenological" perspective overcomes the dangers of classical phenomenology by working out the classical aversion to context-independent truths and radical subject-object distinction in a new way. It considers the "postmodern" reduction of reality to language games, contexts, or other deconstructionist elements to be inadequate as well, since these only confirm the subject-object distinction by stressing the subjective side. Postphenomenology holds that realities come about in relations, as well as the humans that are related to these realities. Like actor-network theory, phenomenology stresses the contingency of reality, and the need for a "relational ontology" where reality is only given in the relations humans have with it.

The main difference between postphenomenology and actor-network theory is that postphenomenology is primarily interested in the relationships between people and the world, instead of the "constructions" that arise in and through them. To ANT, these relationships consist of networks of humans and nonhumans within which reality is constructed; to postphenomenology, they consist of the intentional relationships between humans and their 
world, in which both "objectivity" and "subjectivity" are constituted.7 Postphenomenology does not bridge the "Grand Canyon" between subject and object by blurring the distinction between them - as ANT does, claiming that they are to be treated as semiotically equivalent entities - but by showing that they are intertwined, even at the level of their constitution. Postphenomenology aims to understand the "contact" between humans and world: the experiences and actions in which they co-shape each other.

Seen from the perspective of ANT, postphenomenology might appear to be a very limited approach, since it only studies very short networks. After all, the human-world relationships it analyses involve only two actants: a perceiving or acting human and an actant (human or nonhuman), which is experienced or interacted with. At best, three actants are involved: when technical mediation occurs, a third, nonhuman actant is added to the network. When humans are indicated by an " $\mathrm{H}$ " and nonhumans by " $\mathrm{N}$ ", a postphenomenological perspective on mediation only analyses the networks $\mathrm{H}-\mathrm{NH}$ $\mathrm{NH}$ and $\mathrm{H}-\mathrm{NH}-\mathrm{H}$. But this simplicity is no shortcoming. The fact is that actornetwork theorists could treat each of the three elements of the human-technology-world network as a black box, containing networks of any desired complexity. Postphenomenology does not deconstruct these entities, simply because it asks a different question than AN T does. It is not primarily interested in the networks behind entities, but in the relationships humans can have with them - whether they are constructed or not. Postphenomenology studies these relationships in a more detailed way than ANT investigates the networked connections between actants. Where Latour simply speaks of "associations", postphenomenology studies these associations in a differentiated way. Human-world relationships comprise action and experience, and mediating artifacts can be present in several ways in this relationship, as will become clear below.

\section{Technological intentionality}

The postphenomenological point of view offers new possibilities for understanding mediation by artifacts. It suggests that mediation takes place in human-world relationships: when artifacts are used, they enable and co-shape relationships between humans and their environment. This implies that artifacts do more than mediate action. Action is only one aspect of the relationship between humans and their world, an aspect that becomes visible when approaching this relationship "from the human side", since action can be seen as the way humans can be present in their world. However, the human-world relationship can be approached from the opposite direction as well. Seen 
"from the world side", it concerns the ways in which reality can be present for people. This counterpart to "action" is "experience". The contact between humans and the world, therefore, has two modi: action and experience, aggregating into "ways of existing" (existentially) on the one hand, and "forms of interpretation" (hermeneutically) on the other.

The distinction between action and experience allows an expansion of Latour's analysis of technical mediation. When an artifact is used, it co-shapes human-world relations by giving shape not only to people's actions but also to people's experiences. When using a car, for instance, the car mediates the relationship between a person and his or her world. It lets this person be present as a driver, who's able to move quickly from one place to another. This contributes to the generation of specific forms of existence. A car, for instance, allows people to choose a place to live that is far from work, and maintain social relationships outside their immediate living environment. At the same time, it lets the environment through which he or she drives be present in a specific way. From a car, one cannot smell or hear the environment, instead one receives intense and rapidly changing visual impressions. When I take the bicycle to work, my commuting has a completely different character than when I take the car or walk, as does my relation to the meadows, the cows, and the people I pass. A car not only mediates people's actions but their experiences as well. It co-shapes the ways in which humans can be present in their world and the ways in which reality can be present to humans.

This expanded understanding of mediation invites an expansion of the concept of "script" as well. Within Latour's analysis, scripts are primarily related to action. Scripts concern the translation, inscription, and delegation of programs of action, whereas a concept is needed that indicates mediation in the broadest sense, a mediation of the interrelationship between humans and their world. Don Ihde's concept of "technological intentionality" could serve this purpose, in a slightly adapted way.

With "technological intentionality", Ihde indicates that technologies have "intentions" - they actively shape people's relations with their world. ${ }^{9}$ A pen, for instance, asks for a completely different writing style than a typewriter and a word processor do. With a pen, people tend to write longer, carefully formulated sentences, whereas a typewriter invites a more speech-like style of writing (Ihde 1990, 141-143). As Latour does with "scripts", Ihde implicitly localises this technological intentionality in the things themselves. From a postphenomenological perspective, however, it is more adequate to localise technological intentionality in the relationship between humans and their world. Within classical phenomenology, this relationship has been called "intentionality", as the above section showed. What Ihde in fact brings to light is that 
technologies can create a "technologically mediated" intentionality, a relationship between humans and a world in which their mutual constitution is mediated by technological artifacts. When technologies are used, they coshape human-world relationships: they make possible practices and experiences, and in so doing, they play an active role in the way humans can be present in their world and vice versa. I would like to define "technological intentionality", therefore, as an abbreviation of "technologically mediated intentionality".

This definition of technological intentionality implies that the mediating capacity of artifacts is no essential property of things themselves, but emerges from the interplay of things and their context. Technologies are "multistable", as Ihde observes, in that they are what they are only within the context in which they are used (Ihde 1990, 144-151). What things are, and therefore how they mediate the mutual constitution of people and the world, emerges from people's relationships with them. Mediating things have to be constituted themselves before they can mediate the mutual constitution of people and the world, to phrase it in the vocabulary of classical phenomenology. A revolving door can constitute a building as inaccessible for persons in a wheelchair, and as draught-free for people who are able to enter it. In the first case, it constitutes its user as disabled, in the latter as mobile enough to pass through. The mediating role of the door depends on the kind of relationship someone has with it. Its "stability", and therefore its mediating role, "emerges" from the interplay between the door and its users.

Since technological intentionalities, unlike scripts, are not properties of artifacts themselves, but technologically mediated relationships via artifacts, it is not possible here to reduce artifacts to what was delegated to them by people. Nobody delegated to a revolving door that it should prevent people in wheelchairs from entering the building. Within a postphenomenological perspective, the reduction of nonhumans to humans or the other way round is simply not an option. Humans and the world are distinct and irreducible to each other, but they are nevertheless also inextricably intertwined and coshape each other. Postphenomenology, in other words, does not abolish the distinction between humans and nonhumans, but shows their fundamental connectedness and interrelatedness. Artifacts mediate ways of existence (subjectivities) and experienced realities (objectivities) not because people told them to do so, but because of the relation between humans and the world that comes about through them. 


\section{Engaging mediators}

The postphenomenological perspective on mediation allows for an approach to artifacts in which their mediating role is not reduced to what humans delegate to them. Localising the mediating role of artifacts in the interplay between humans and the world grants things the degree of independence they deserve. Although they do not autonomously shape human-world relations, their role cannot be entirely reduced to "non-thingly" factors.

The postphenomenological perspective on mediation, therefore, does justice to the materiality of things, and this might make it useful to Eternally Yours. What Eternally Yours needs, after all, is an approach to things that, in contrast to the predominant focus on functionality and meaningfulness within industrial design, focusses on the relationships between people and things themselves.

Earlier in this chapter, it became clear that in order to be "eternally ours", things should evoke engagement with themselves as material entities. To accomplish this, it was said, products could be designed in such a way that they engage people in their functioning. A postphenomenological perspective on human-artifact relationships can shed more light on this engagement, and therefore it might be helpful when looking for ways to stimulate it. In order to understand situations in which things involve people in their functioning situations that in a Latourian vocabulary could be called "delegations from nonhumans to humans" - another (but short) expansion of the theory of technical mediation has to be made. In order to understand engagement with products, it is not only necessary to understand how artifacts mediate human-world relationships, but also how they are present for people when they do so.

Things mediate human-world relationships when they are used, and things-in-use are present in a peculiar way: they are present and absent simultaneously. When a technology is used, people's attention is not directed at the technology itself, but at what they can do or experience by means of it. If this were different, after all, it would not be possible to use things. Technologies only draw attention to themselves when they break down. When hammering a nail into the wall, people's attention is not directed at the hammer, but at the nail; only when the head comes loose from the handle does the hammer ask for attention. Heidegger called these two modes of human-artifact relations "readiness-to-hand" (zuhandenheit - artifacts-in-use) and "presence-at-hand" (vorhandenheit - artifacts asking attention for themselves). ${ }^{10}$

The distinction between being "ready to hand" and "present at hand" can 
be a starting point for understanding the relationship between humans and "engaging objects". The fact is that engaging objects merge these two modes of thingly presence in a specific way. From the perspective of Heidegger's distinction, the concept of "engaging technologies" might seem paradoxical at first sight. After all, how can a technology withdraw and at the same time ask for involvement and engagement with itself? From what has been stated above, it seems to follow that technologies that ask for involvement with themselves cannot be used at all because people's attention can only be directed at the object itself, not at what could be done by means of it. But, engaging technologies do exist. Artifacts that can ask for involvement do not necessarily have to be entirely present-at-hand.

Compare, for instance, a piano with a CD player. A CD player in use is ready-to-hand in that it withdraws from people's attention and becomes transparent in order to give access to the music it plays. A broken CD player is present-at-hand in that it is not transparent but opaque, because it blocks people's access to the music it could play if it worked. The way in which a piano is present combines these two modi of presence. It is ready-to-hand, but still engages people in its functioning. If it were not ready-to-hand, it could not give access to the music that can be played on it. Only when someone is learning to play is the piano present-at-hand, and the piano player's attention is only directed toward the piano itself. After this learning stage, the piano player becomes engaged with the music he or she plays on the piano. The piano never completely withdraws, however. In order to be played, it asks for a lot of involvement as a physical entity. Whereas a CD player only asks you to press a button, a piano demands an intense bodily engagement of the player.

An important dimension of this "engaging capacity" of artifacts is the skill that is needed to interact with them. Skill can be seen as the effort needed to "appropriate" artifacts. What sets a piano apart from a CD player is the degree of skill that is required to use it. To use a CD player, one only has to know how to turn it on and off. Once the $\mathrm{CD}$ is playing, no skill is required to listen to the music. This degree of engagement does not require skill. The most important aspect of engagement with artifacts - which is also central in acquiring skill is the necessity to interact with its machinery. The engagement a piano evokes is not comparable to the interaction with, for instance, a hammer. A hammer does not require active engagement with its machinery. For someone who has learned to use and "incorporate" a hammer, it becomes an extension of the body. A piano, by contrast, never becomes an extension of the body, even for the best piano players. It requires active and concentrated interaction with its keys and pedals, and therefore it never withdraws from a player's intentionality relationship with his or her world. 
The possibility of an "engaging presence of things" can be of importance for Eternally Yours. ${ }^{11}$ Artifacts can invite relations with themselves, making possible engaging practices in which they partly withdraw from people's attention, but yet still involve users in their functioning. In such cases, artifacts mediate people's relationship not only with their world, but also with the artifacts themselves. This type of mediation can provoke attachment to the materiality of things - the kind of attachment that would be helpful for Eternally Yours.

Such engaged ways of interacting with objects also play an important role in Gomart and Hennion's aforementioned research on "attachment". A postphenomenological perspective could enrich the vocabulary for analyses like theirs, since it offers concepts for understanding the way artifacts are present in events of attachment. Artifacts are the "locus" of such events, as Gomart and Hennion say, but this locus is by no means static and passive. Attachment comes about when artifacts invite engagement with themselves, and at the same time create scope for people to experience and interact with the world around them. They are somewhere in between "presence-at-hand", by asking for engagement, and "readiness-to-hand", by allowing humans to do something with them instead of only interacting with the artifacts themselves.

However, looking at products in terms of their "engaging capacity" is far from obvious. Most technological products avoid provoking engagement. This is quite understandable, since people usually do not use technologies in order to be engaged, but to be disburdened. As the philosopher of technology Albert Borgmann shows, technologies tend to put their machinery in the background in order to allow people to enjoy the commodities they procure as quickly, easily, safely and ubiquitously as possible (Borgmann 1984, 41). Technologies do things for us, instead of asking things from us. We prefer a water tap to a well, because a tap does not require us to take a walk, lower a bucket, haul it up again, and walk back home. A tap only asks for a simple, hardly noticeable action in order to obtain water. This is the typical pattern of technology - it creates the availability of commodities by diminishing the need for involvement in their materialisation.

From this perspective, the challenge for culturally sustainable design is to break this consumptive pattern in a playful way. In order to evoke attachment, things should ask for engagement instead of the mere consumption of their commodities. An attractive example of such engaging products is the award-winning "electric/ceramic heater", designed by Sven Adolph at Cranbrook Academy of the Arts (Chicago). It consists of a heating element surrounded by several concentric, cylindrically shaped ceramic shells of various heights, each with a vertical aperture. The shells can be arranged in several 
ways, so that they radiate their warmth in different directions. This artifact is not a purely functional heater that withdraws into pure functionality, like common radiators, which are usually hidden under the windowsill and only ask to be turned on and off. Adolph's shell heater is an engaging product that asks for attention and involvement in its functioning. It is intended to be placed in the middle of the room as if it were a campfire. You cannot escape it if you need warmth, because you have to sit around it. Its shells have to be arranged in a certain way if we want it to function. Simply turning the heater on and off is not enough; you actually have to get involved in its functioning if you want it to work.

Another interesting example of engaging products is Donald Carr's "Ithaca Color Printer", also designed at Cranbrook Academy. It is a colours inkjet printer with entirely transparent machinery. It possesses four reservoirs, for black, yellow, red, and blue ink, and the printer head remains visible when it is functioning. The open architecture of this printer not only makes it fascinating to watch the printing process - which would not be enough to evoke durable attachment - it also makes the functioning of the printer understandable, and it is therefore able to involve humans in its functioning. It can be refilled with ink when needed, and if mechanical problems occur, they can easily be fixed.

When handling Adolph's heater and Carr's printer, users are confronted with the materiality of these products. They are not present simply as providers of warmth or printed text. Users are playfully forced to participate in the processes that make these commodities available and in which the machinery of products plays a central role. Engaging products do not make themselves invisible. They maintain present in people's attention during use, without being present in the foreground of our experience.

\section{Conclusion}

The ambition of the Dutch industrial-designer association Eternally Yours to find ways of designing "culturally sustainable" products shows several opportunities for expanding Latour's theory of technical mediation. First, Eternally Yours makes visible the need to expand the concept of delegation, so that it covers delegations from nonhumans to humans as well. These nonhuman delegations could play an important role in the attachment between humans and things. For this attachment to come about, products could delegate the responsibility for parts of their functioning from their machinery to their users. In this way, users are engaged with the materiality of products, not only 
with their functionality or meaningfulness - which are the predominant foci in current industrial design.

Second, it became clear that the concept of "script" should be expanded to "technological intentionality", in order to be able to localise the "mediating capacity" not in the artifacts themselves, but in the relationship between humans and their environment that is enabled and mediated by these artifacts. "Scripts" or "technological intentionalities" should not be seen as properties of artifacts, but as features of configurations of humans and things, in which some actions are stimulated and others prohibited.

Third, it has become clear that "mediation" concerns not only action but experience as well.

The contours of a postphenomenological perspective on technical mediation have been sketched to allow for these expansions. This perspective also enabled a closer analysis of the attachment between humans and artifacts that Eternally Yours is trying to stimulate. For attachment to come about, artifacts should be present in an engaging way. They should stimulate users to participate in their functioning, thus forging a bond between users and the machinery of artifacts. Engaging artifacts are not present simply as generators of commodities. Their materiality cannot be avoided because humans have to enter into a relationship with the product itself, not only with what it does for them. And only if the product itself matters - instead of its "meaning", "image", or "functionality" - will it be less likely to be readily discarded. Its meaning, image, and functionality can also be procured by similar products.

Understanding the attachment between humans and artifacts requires an attachment of actor-network theory to phenomenology.

\section{Notes}

1 I mention his work here, even though Latour recently renounced the name "actor-network theory" because of the misleading associations that have become connected with the concepts of "actor", "network", "theory", and even the hyphen between "actor" and "theory" (Latour 1999b).

2 More information about Eternally Yours can be found at: http://www.ecomarket.net/EternallyYours.

3 Ihde uses this term for his "praxis-perception model" of phenomenology, in which phenomenology primarily concerns the perceptual aspects of humanworld relations (Ihde 1993, 3, 7; Ihde 1990, 30). In his introduction to postphenomenology, he indicates that his phenomenological model can be ranged 
among the "posts" that have developed in philosophy, because of its pluralism and nonfoundationalism $(1993,1)$. He does not elaborate on the implications of this turn for the methods and characteristics of the phenomenological approach itself, however. That is why I try to do so here, by setting out the keynotes of what I think postphenomenology should consist of.

4 “Tout l'univers de la science est construit sur le monde vécu." (Merleau-Ponty 1945, III)

5 "Il s'agit de décrire, et non pas d'expliquer ni d'analyser." (Merleau-Ponty 1945, IV)

6 In this context, "world" indicates "disclosed reality": or a reality as it is present to humans in concrete situations, not "reality in itself".

7 This postphenomenological idea of the mutual constitution of subject and object escapes Latour's criticism on phenomenology in We Have Never Been Modern. Latour maintains that, by connecting them to each other over the bridge of intentionality, phenomenology confirms the "poles" of subject and object instead of refuting them. Postphenomenology, however, sees the two poles as the product of the intentional relation between them, not as pre-existing subjects and objects. Subjectivity and objectivity arise from their interrelatedness, instead of being presupposed by it.

8 See Latour $(1993 \mathrm{~b}, 39)$ for an extended use of this kind of annotation.

9 See also Verbeek (2001).

10 See Heidegger (1986, paragraph 15 and 16).

11 See also Verbeek and Kockelkoren (1998). 